\title{
New $\left[\mathrm{LNi}_{2}{ }_{2}\right]^{+}$Complexes Incorporating 2-Formyl or 2,6- Diformyl-4-Methyl Phenol as Inhibitors of the Hydrolysis of the Ligand $\mathrm{L}^{3-}$ : $\mathrm{Ni} \cdots \mathrm{Ni}$ Ferromagnetic Coupling and $\mathrm{S}=2$ Ground States
}

Alok Ranjan Paital, ${ }^{\ddagger}$ Wing Tak Wong, ${ }^{\dagger}$ Guillem Aromí ${ }^{*, 8}$ and Debashis Ray, ${ }^{*}$

${ }^{\ddagger}$ Department of Chemistry, Indian Institute of Technology, Kharagpur 721 302, India,

${ }^{\dagger}$ Department of Chemistry, University of Hong Kong, Pokfulam Road, Pokfulam, Hong

Kong SAR, P.R. China, and ${ }^{\S}$ Departament de Química Inorgànica, Universitat de

Barcelona, Diagonal, 647 08028-Barcelona, Spain

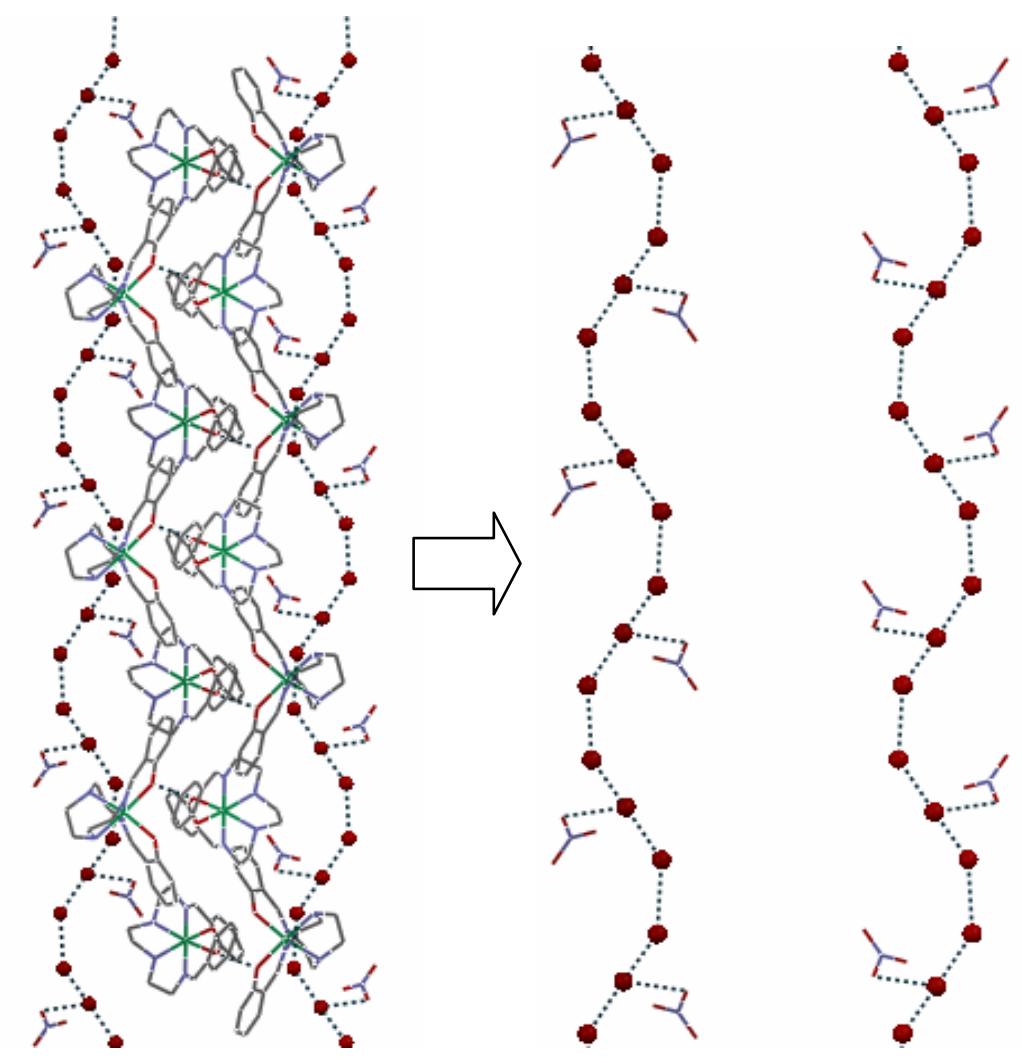

Figure S1. Intermolecular anion-water hydrogen bonding in complex 1 gives a 1-D net running along the crystallographic a-axis. 


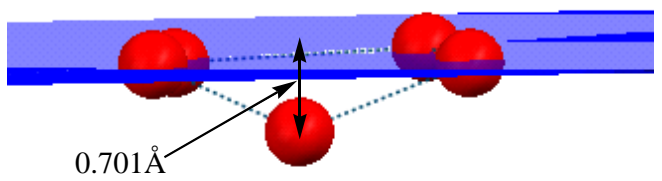

Figure S2. Like cyclopentane one water oxygen (O9W) is $0.701 \AA$ below the water cluster plane in complex 2.

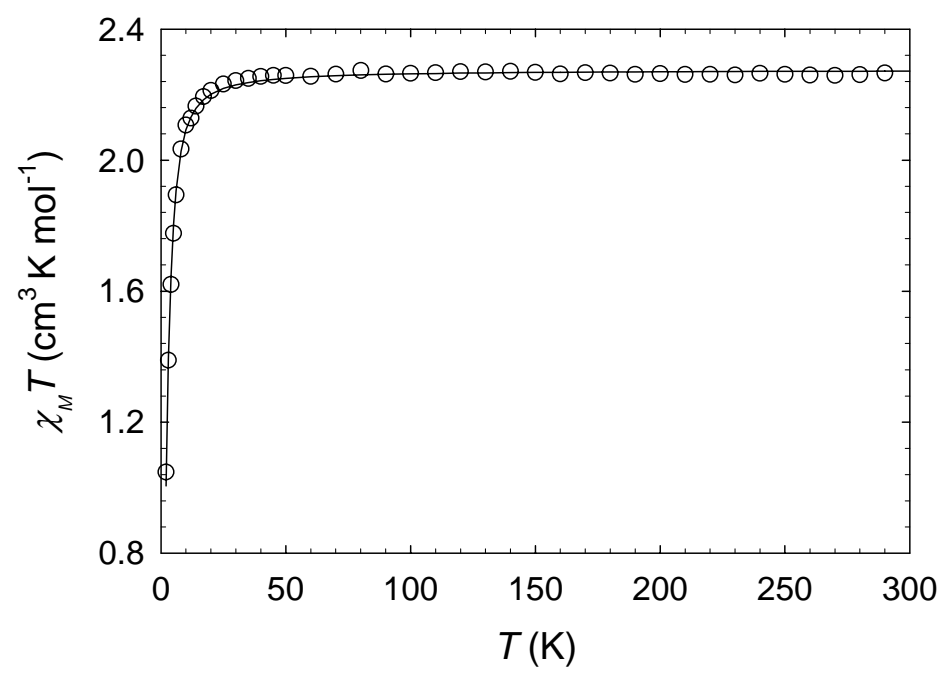

Figure S3. Plot of $\chi_{M} T$ vs $T$ per mol of $[\mathrm{Ni}(\mathrm{HL} 1)]_{2}\left(\mathrm{NO}_{3}\right)_{2}$ (1). The solid line is a fit to the experimental data using a model that includes $\mathrm{Ni}^{\mathrm{II}} \cdots \mathrm{Ni}^{\mathrm{II}}$ superexchange and single ion zero field splitting (see text for details). 


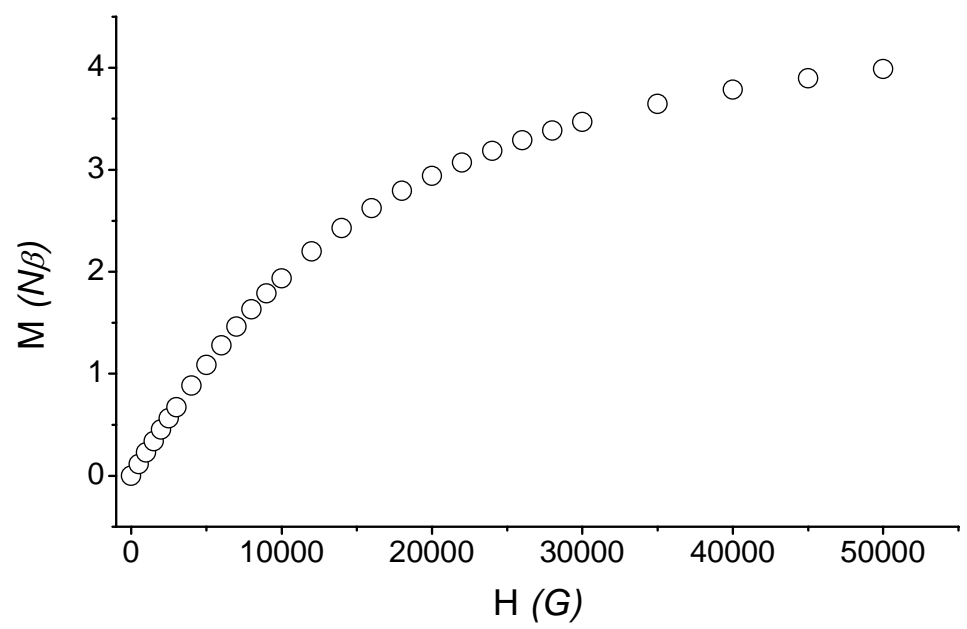

Figure S4. Plot of isothermal (2K) reduced magnetization vs magnetic field for complex $\left[\mathrm{Ni}_{2}(\mathrm{~L})(\mathrm{fp})\left(\mathrm{H}_{2} \mathrm{O}\right)\right](2)$.

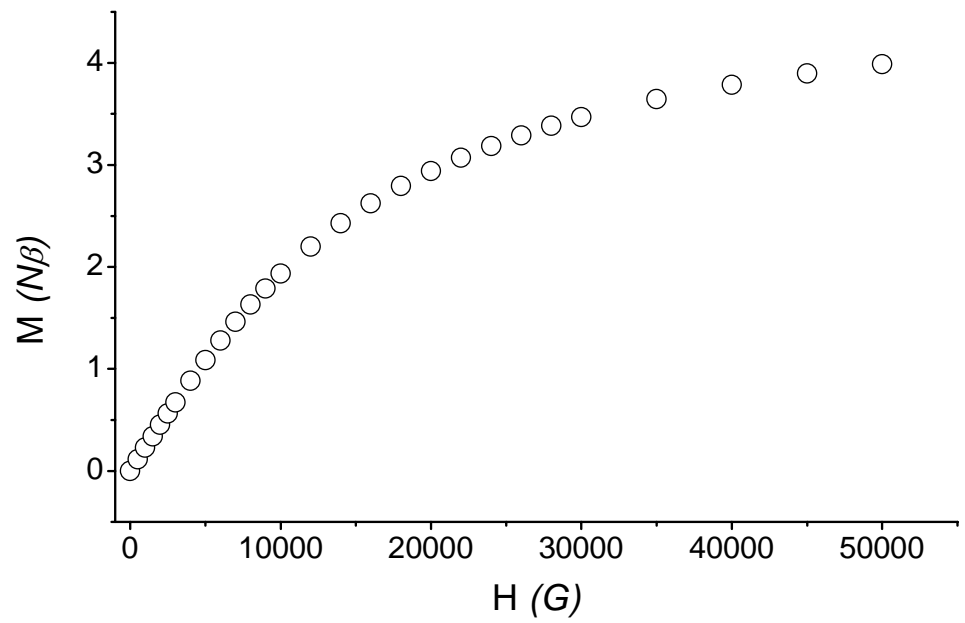

Figure S5. Plot of isothermal (2K) reduced magnetization vs magnetic field for complex $\left[\mathrm{Ni}_{2}(\mathrm{~L})(\mathrm{dfp})\right](3)$. 